University of Nebraska - Lincoln

DigitalCommons@University of Nebraska - Lincoln

$1-1985$

\title{
Cross Sections for Ionization of Water Vapor by 7-4000-keV Protons
}

M. Eugene Rudd

University of Nebraska - Lincoln, erudd@unl.edu

T. V. Goffe

University of Nebraska - Lincoln

R. D. DuBois

PaciJic Northwest Laboratories, Richland, Washington

L. H. Toburen

PaciJic Northwest Laboratories, Richland, Washington

Follow this and additional works at: https://digitalcommons.unl.edu/physicsrudd

Part of the Physics Commons

Rudd, M. Eugene; Goffe, T. V.; DuBois, R. D.; and Toburen, L. H., "Cross Sections for Ionization of Water Vapor by 7-4000-keV Protons" (1985). M. Eugene Rudd Publications. 12.

https://digitalcommons.unl.edu/physicsrudd/12

This Article is brought to you for free and open access by the Research Papers in Physics and Astronomy at DigitalCommons@University of Nebraska - Lincoln. It has been accepted for inclusion in M. Eugene Rudd Publications by an authorized administrator of DigitalCommons@University of Nebraska - Lincoln. 


\title{
Cross sections for ionization of water vapor by $7-4000-\mathrm{keV}$ protons
}

\author{
M. E. Rudd and T. V. Goffe* \\ University of Nebraska-Lincoln, Lincoln, Nebraska 68588-0111 \\ R. D. DuBois and L. H. Toburen \\ Pacific Northwest Laboratories, Richland, Washington 99352
}

(Received 27 August 1984)

\begin{abstract}
Cross sections for production of electrons and positive ions by proton impact on water vapor have been
\end{abstract} measured from $7-4000 \mathrm{keV}$ by the transverse-field method.

\section{INTRODUCTION}

Although information on the ionization of water molecules is fundamental in studies of the interaction of energetic particles with biological material, cross sections for ionization of water vapor by ions are extremely scarce. Toburen and Wilson ${ }^{1}$ have measured doubly differential cross sections for $300-1500-\mathrm{keV}$ protons on water vapor, but because of uncertainties in the data at low electron energies, no total cross sections were presented. Toburen, Wilson, and Popowich ${ }^{2}$ have made similar measurements for $\mathrm{He}^{+}$ and $\mathrm{He}^{2+}$ ions from 300 to $2000 \mathrm{keV}$.

In the present work we have made measurements of $\sigma_{+}$ and $\sigma_{-}$by the transverse-field or parallel-plate-capacitor method using four different accelerators at the Pacific Northwest Laboratories (PNL) and the University of Nebraska-Lincoln (UNL). This is an extension of a recently reported project ${ }^{3}$ in which 10 other gas targets were used. The present measurements cover the energy range 7-4000 $\mathrm{keV}$ using the same gas cell and electrode apparatus.

\section{EXPERIMENTAL PROCEDURE}

Since the experimental apparatus and procedure have been described in detail previously, ${ }^{3}$ we will not repeat the description here.

The water used to prepare the target was distilled or deionized water from which dissolved gases were eliminated by the freeze-pump-thaw method. The water was frozen by liquid nitrogen while air and other gases were pumped away. The pump was then valved off and the water warmed up to drive out any remaining dissolved gas. The process was then repeated two or three times before use. During some later runs, a quadrupole gas analyzer was used to check the purity of the target.

Two runs were made on the PNL Van de Graaff accelerator, the early run from 200 to $2000 \mathrm{keV}$ and the later one from 100 to $2000 \mathrm{keV}$. The PNL low-energy accelerator covered the range of $7-100 \mathrm{keV}$, while the tandem Van de Graaff accelerator went from 2000 to $4000 \mathrm{keV}$. Two runs were made on the UNL accelerator, both from 40 to 350 $\mathrm{keV}$.

Between the two Van de Graaff runs, additional shielding was added to the electrode assembly. The later UNL run benefited from the addition of the quadrupole gas analyzer which detected a small leak in the gas line which may have been present in the earlier run.

\section{EXPERIMENTAL RESULTS}

The values of $\sigma$ - for the six runs are shown in Fig. 1. In order to obtain a smooth average to the energy dependence, the following procedure was used. First, a weight was assigned to the data in each run based on our estimate of the systematic erorrs. Then a preliminary least-squares fit was made by computer to the equation

$$
\sigma\left(E_{p}\right)=1 /\left(1 / \sigma_{l}+1 / \sigma_{h}\right)
$$

where

$$
\sigma_{l}=4 \pi a_{0}^{2} C x^{D}
$$

and

$$
\sigma_{h}=4 \pi a_{0}^{2}[A \ln (1+x)+B] / x,
$$

with $x=T / R, T=E_{p} / 1836, R=13.6 \mathrm{eV}, a_{0}$ the Bohr radius, and $E_{p}$ the proton energy. $A, B, C$, and $D$ are the adjustable fitting parameters. This form of the fitting equation has the same high-energy dependence as the Bethe equation and the parameter $A$, which is equal to the optical oscillator strength, can be compared with other measurements of that quantity. As before, the rms fractional deviation was minimized in the fitting procedure.

Next, for each run we calculated an adjustment factor $f_{j}$

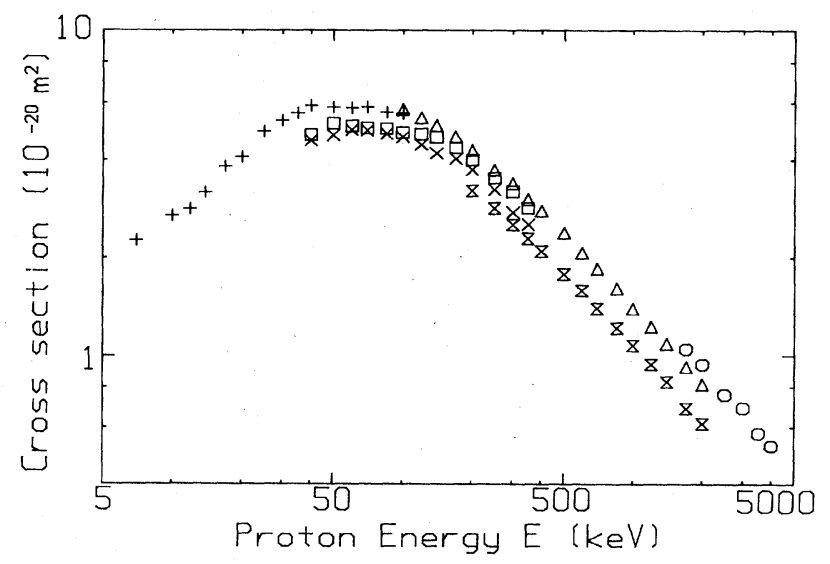

FIG. 1. Measured cross sections $\sigma_{-}$vs proton energy for water vapor. Low-energy accelerator, +; early Van de Graaff data, $\mathbf{~}$; late Van de Graaff data, $\Delta$; early UNL data, $\square$; late UNL data, $\times$; tandem Van de Graaff data, $O$. 
TABLE I. Weights and adjustment factors.

\begin{tabular}{lcc}
\hline \hline Data set $^{\mathrm{a}}$ & Weight & Adjustment Factor \\
\hline LOW & 10 & 0.915 \\
NUE & 8 & 1.037 \\
NUL & 10 & 1.114 \\
VER & 4 & 1.255 \\
VLA & 10 & 0.945 \\
TVD & 6 & 0.824 \\
\hline \hline
\end{tabular}

${ }^{a}$ LOW is the data set taken on the low-energy acclerator; NUE is the early and NUL the later run on the Nebraska accelerator; VER is the early and VLA the later Van de Graaff data; TVD is the data taken on the tandem Van de Graaff accelerator.

which minimized the fractional deviation of that run from the fitted curve of Eq. (1). If we let $\sigma_{j}\left(E_{p}\right)$ represent the cross section at energy $E$ measured in run $j$, and let $\sigma\left(E_{p}\right)$ be the cross section calculated from Eq. (1), then the quantity minimized was

$$
\sum_{E_{p}}\left[1-f_{j}^{\prime} \sigma_{j}\left(E_{p}\right) / \sigma\left(E_{p}\right)\right]^{2}
$$

for each set $j$. This condition determined the factors

$$
f_{j}^{\prime}=\frac{\sum_{E_{p}} \sigma_{j}\left(E_{p}\right) / \sigma\left(E_{p}\right)}{\sum_{E_{p}} \sigma_{j}^{2}\left(E_{p}\right) / \sigma^{2}\left(E_{p}\right)} .
$$

Furthermore, to ensure that there be no overall scaling of the data, we also required that the weighted average of the adjustment factors be unity. This was ensured by setting

$$
f_{j}=f_{j}^{\prime} \sum_{j} W_{j} / \sum_{j} W_{j} f_{j}^{\prime}
$$

where $W_{j}$ is the weight for the data in the $j$ th run. The weights assigned to the various runs are given in Table I.

The fitting and adjusting process was then repeated, using the new adjustment factors for the fitting and the new fitting parameters in the adjustment, until the factors and the parameters stabilized. This required 4-5 iterations. This method has the advantage over the simpler fitting method

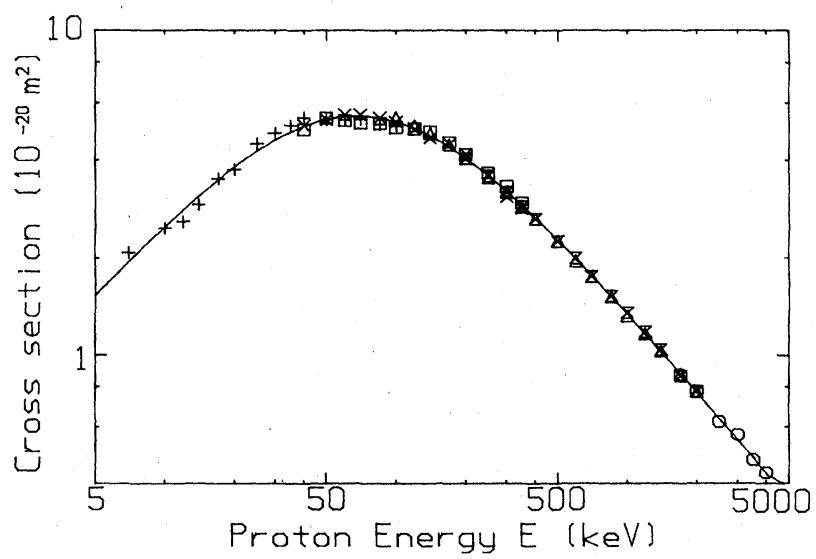

FIG. 2. Cross sections $\sigma_{-}$after adjustment of data (see text). Solid line is the fit using Eq. (1). Symbols as in Fig. 1.
TABLE II. Parameters for the fitting equations.

\begin{tabular}{ccc}
\hline Parameter & $\sigma_{-}$[Eq. (1)] & $\sigma_{+}$[Eqs. (1) and (4)] \\
\hline$A$ & 2.98 & 2.98 \\
$B$ & 4.42 & 4.42 \\
$C$ & 1.48 & 1.48 \\
$D$ & 0.75 & 0.75 \\
$F$ & $1 . .5 \%$ & 4.80 \\
rms dev. ${ }^{\mathrm{a}}$ & $11.5 \%$ & $12.6 \%$ \\
rms dev. & $2.7 \%$ & $5.1 \%$ \\
\hline \hline
\end{tabular}

annadjusted data.

${ }^{\mathrm{b}}$ Adjusted data.

used previously ${ }^{3}$ that the shape of the curve is not distorted by averaging over runs in different energy ranges which have various systematic errors.

The results of this averaging process applied to the $\sigma_{-}$ data are shown in Fig. 2, where the cross sections in each data set have been multiplied by their adjustment factors, given in Table $I$. It can be seen that the results lie close to a universal curve which is approximated by the final fit given by Eq. (1), shown as the line. The parameters of the fit are also given in Table II.

The adjustment factors $f_{j}$ calculated for the $\sigma$ - cross sections, as described above, were then applied to the $\sigma+$ measured cross sections. These were then fitted to Eq. (1) modified slightly by making

$$
\sigma_{l}=4 \pi a_{0}^{2}\left(C x^{D}+F\right)
$$

and using the values of $A, B, C$, and $D$ shown in Table II. The resulting cross sections and fit are plotted in Fig. 3 . Table III gives values of the cross sections computed from Eqs. (1) and (4).

While the capture cross section $\sigma_{c}$ can be obtained from the relation

$$
\sigma_{c}=\sigma_{+}-\sigma_{-},
$$

values obtained in that way are not very accurate especially above $100 \mathrm{keV}$ since they are obtained by subtracting two quantities which are close in value.

The analysis of experimental uncertainties here is the

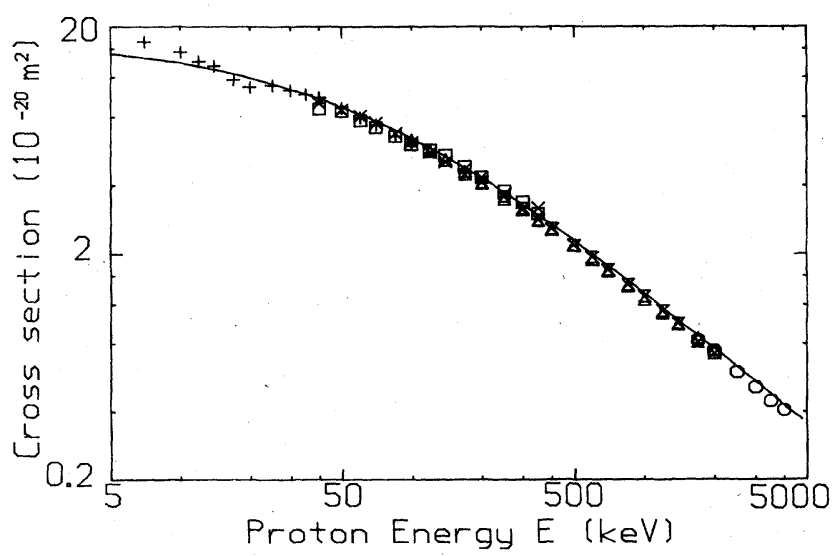

FIG. 3. Cross sections $\sigma_{+}$after adjustment of data. Solid line is the fit using Eqs. (1) and (4). Symbols as in Fig. 1. 
TABLE III. Values of $\sigma_{-}$and $\sigma_{+}$from Eqs. (1) and (4) in units of $10^{-20} \mathrm{~m}^{2}$.

\begin{tabular}{rcc}
\hline \hline $\begin{array}{c}\text { Energy } \\
(\mathrm{keV})\end{array}$ & $\sigma_{-}$ & $\sigma_{+}$ \\
\hline 7 & 1.94 & 14.6 \\
10 & 2.48 & 13.8 \\
15 & 3.22 & 12.8 \\
20 & 3.79 & 11.9 \\
30 & 4.59 & 10.6 \\
50 & 5.32 & 8.86 \\
70 & 5.45 & 7.68 \\
100 & 5.23 & 6.46 \\
150 & 4.61 & 5.16 \\
200 & 4.04 & 4.32 \\
300 & 3.20 & 3.31 \\
500 & 2.26 & 2.29 \\
700 & 1.77 & 1.78 \\
1000 & 1.34 & 1.34 \\
1500 & 0.969 & 0.97 \\
2000 & 0.766 & 0.767 \\
3000 & 0.547 & 0.547 \\
5000 & 0.355 & 0.355 \\
\hline \hline
\end{tabular}

same as in the previous work, ${ }^{3}$ and will not be repeated. Although the adjusting and fitting procedure described above should be an improvement over the previous method, we will still assign the same overall uncertainties to the results obtained from the fitting equations, namely, $20 \%$ at $10 \mathrm{keV}, 15 \%$ at $25 \mathrm{keV}, 10 \%$ at $100 \mathrm{keV}$, and $8 \%$ above $500 \mathrm{keV}$.

\section{DISCUSSION OF RESULTS}

To our knowledge, there are no previously published total cross-section measurements for protons on water vapor with which we can compare our results.

As previously mentioned, the parameter $A$ can be directly compared to the optical oscillator strength $M_{i}^{2}$ obtained by other methods. The relation between the photoionization cross section $\sigma_{\mathrm{ph}}(\lambda)$ and the oscillator strength given by Berkowitz, ${ }^{4}$ is

$$
M_{i}^{2}=0.12396 \int_{0}^{\lambda_{0}} \sigma_{\mathrm{ph}}(\lambda) d \lambda / \lambda,
$$

where the threshold wavelength $\lambda_{0}$ for water vapor is $985 \AA$.

Schutten et al..$^{5}$ have integrated data of Wainfan, Walker, and Weissler ${ }^{6}$ from 473 to $985 \AA$ and, extrapolating to zero wavelength, they obtain an estimate of 2.59 for $M_{i}^{2}$. New photoionization data by Samson and Haddad $^{7}$ from 104.7 to $985 \AA$ allow a determination of the integral with a much smaller extrapolation uncertainty. This gives $M_{i}^{2}$ of 2.93 with a measurement uncertainty of $3 \%$ and an uncertainty in integration of $2 \%$. This result is in excellent agreement with our value of $A$ which is 2.98 . It also agrees well with the value of 3.14 obtained by Schutten et al. ${ }^{5}$ by electron impact ionization.

\section{ACKNOWLEDGMENTS}

This paper is based on work performed under National Science Foundation Grant No. PHY-80-25599 and the U.S. Department of Energy Contract No. DE-AC06-76RL0-1830. The authors wish to thank J. A. R. Samson for the use of his unpublished photoionization data.
"Present address: 3 Eglantine Park, Hillsborough, County Down BT26.6HL, North Ireland.

${ }^{1}$ L. H. Toburen and W. E. Wilson, J. Chem. Phys. 66, 5202 (1977).

${ }^{2}$ L. H. Toburen, W. E. Wilson, and R. J. Popowich, Radiat. Res. 82, 27 (1980).

${ }^{3}$ M. E. Rudd, R. D. DuBois, L. H. Toburen, C. A. Ratcliffe, and T. V. Goffe, Phys. Rev. A 28, 3244 (1983).
${ }^{4}$ Joseph Berkowitz, Photoabsorption, Photoionization, and Photoelectron Spectroscopy (Academic, New York, 1979).

${ }^{5}$ J. Schutten, F. J. DeHeer, H. R. Moustafa, A. J. H. Boerboom, and J. Kistemaker, J. Chem. Phys. 44, 3924 (1966).

${ }^{6}$ N. Wainfan, W. C. Walker, and G. L. Weissler, Phys. Rev. 99, 542 (1955).

7J. A. R. Samson and G. N. Haddad (private communication). 